\title{
O Design estratégico e a sustentabilidade no desenvolvimento de embalagens: Case Natura Sou
}

Strategic design and sustainability in case development: Case Natura Sou

\author{
ALMEIDA, Tamara B. H. de; Bacharel em Publicidade e Propaganda; FACCAT \\ tamarab.huff@gmail.com \\ DIEHL, Marcia Regina; Mestre em Design Estratégico; FACCAT \\ marcia@faccat.br
}

\section{Resumo}

Neste artigo buscou-se aprofundar os conhecimentos sobre o design estratégico e a sustentabilidade no desenvolvimento de embalagens. Teve-se como objetivo entender a percepção do consumidor da cidade de Três Coroas sobre a sustentabilidade aplicada nas embalagens da linha de produtos Natura Sou, alcançada por meio do design estratégico. Na análise dos dados coletados através de grupo focal foi possível concluir que a marca, a qualidade dos produtos, o preço e a sustentabilidade são fatores decisórios nas compras dos consumidores analisados. Os resultados alcançados evidenciam a necessidade de ampliar a pesquisa com abrangência maior de regiões a fim de comparar os resultados obtidos, como também coletar dados de pessoas que não consomem os produtos da linha Natura Sou, com o propósito de avaliar suas percepções quanto a sustentabilidade das embalagens estudadas.

Palavras Chave: design estratégico; sustentabilidade; embalagem; decisão de compra.

\begin{abstract}
In this article we sought to deepen our knowledge about strategic design and sustainability in the development of packaging. The objective was to understand the perception of the consumer of the city of Três Coroas on the sustainability applied in the packaging of the Natura Sou product line, achieved through the strategic design. In the analysis of the data collected through a focus group, it was possible to conclude that the brand, the quality of the products, the price and the sustainability are decisive factors in the purchases of the analyzed consumers. The results show the need to expand the research with a greater range of regions in order to compare the results obtained, as well as collect data from people who do not consume the products of the Natura Sou line, in order to evaluate their perceptions regarding the sustainability of the packages studied.
\end{abstract}

Keywords: strategic design; sustainability; packing; buying decision. 


\section{Introdução}

De um lado, temos as empresas que desempenham um papel muito importante no estímulo de mudança em direção à sustentabilidade. Segundo Manzini (2011), essa situação somente pode acontecer enquanto sua postura não interferir na competitividade das organizações. Segundo o autor, caminhar em direção à sustentabilidade implica em mudanças na ideia de produtos e na forma de produzi-los, tais produtos devem responder à necessidade de bem-estar do consumidor, usando o mínimo de recursos ambientais possíveis.

Segundo Manzini (2008), os limites do planeta tornaram-se evidentes. Ainda segundo o mesmo autor, os recursos naturais tornam-se cada vez mais escassos, reduzindo consideravelmente o capital natural do planeta. Ao instituir a sustentabilidade como um diferencial de negócio, a Natura Cosméticos considerou o design estratégico em sua concepção, com o objetivo de aprimorar cada etapa da cadeia produtiva, reduzindo custos, lixo, gasto de energia e transporte e, consequentemente, menos poluição. A marca propõe um novo jeito de consumir: mais consciente, diminuindo o desperdício e valorizando o essencial, sem perder a qualidade (NATURA, 2013).

Desse modo, o trabalho foi organizado com o objetivo geral de identificar a influência que a sustentabilidade das embalagens da linha Natura Sou exerce sobre a decisão de compra dos consumidores Natura da cidade de Três Coroas. A fim de trazer mais clareza e compreensão ao objeto de estudo, foram definidos quatro objetivos específicos: apresentar a relevância da sustentabilidade no desenvolvimento de embalagens, apontar a importância do design estratégico no desenvolvimento de produtos sustentáveis, identificar as características de sustentabilidade nas embalagens da marca Natura Sou, relatar a percepção dos consumidores da linha Natura Sou da cidade de Três Coroas sobre suas embalagens.

Com base nas informações apresentadas, a escolha do tema explica-se pelo interesse em entender a percepção do consumidor da cidade de Três Coroas sobre a sustentabilidade aplicada nas embalagens da linha de produtos Natura Sou. Sendo que, para o estudo em questão, a coleta de dados da pesquisa foi realizada através de grupo focal, com consumidores da linha de produtos Natura Sou, residentes na cidade de Três Coroas.

\section{Sustentabilidade}

Pensando na importância da consciência e atitudes de preservação das riquezas naturais, Almeida (2002) define sustentabilidade como uma forma de sobrevivência, entendida como a continuidade dos empreendimentos humanos e, ainda, do planeta.

O uso do termo sustentabilidade representa a intenção de destacar maior amplitude do conceito em relação à melhora da qualidade da vida, dentro dos limites ambientais do planeta que não esteja apenas associada ao sentido pejorativo de desenvolvimento; que remete ao crescimento econômico, mas que seja levada sempre em consideração por alternativas economicamente viáveis, que sejam socialmente justas e ambientalmente corretas para a construção de uma sociedade sustentável (MARIOTTI, 2013).

A sustentabilidade depende também da base cultural, fundamentada em padrões de consumo e estilos de vida que podem ser considerados perduráveis, pois se baseiam em escolhas conscientes de consumo. Para o autor, essa situação não ocorre com os moldes de desenvolvimento consumista dos países industrializados que, se forem mantidos por toda 
humanidade, levariam a escassez dos recursos naturais (RIBEIRO, 2003).

Em 1992, 172 governos reuniram-se na cidade brasileira do Rio de Janeiro para a Conferência das Nações Unidas para o Meio Ambiente e Desenvolvimento (CNUMAD), que se tornou conhecida como Conferência da Terra, num evento se tornou marco histórico para a humanidade. Os principais objetivos da Conferência eram alcançar um justo equilíbrio entre as necessidades econômicas, sociais e ambientais das gerações atuais e futuras e firmar as bases para uma aposição mundial entre os países desenvolvidos e em desenvolvimento, assim como entre os governos e os setores da sociedade civil, concentradas na compreensão das necessidades e dos interesses comuns (RAMOS, 2003).

Através da Conferência da Terra, pode-se destacar que o Brasil é sempre visto como um dos principais atores nas tratativas internacionais sobre esses temas e as posições defendidas pelo país são, invariavelmente, acolhidas com respeito e atenção. Essa relação decorre de suas próprias credenciais, ligadas ao seu peso político e econômico, mas principalmente das riquezas e da diversidade de seu patrimônio ambiental (ALMEIDA, 2002).

Segundo Bauman (2011), a vida e a liberdade dos seres humanos estão em crise. De acordo com o autor, a relação entre homem e natureza está entrando em colapso, e este é um assunto que vem sendo debatido tanto em âmbito nacional quanto internacional. Ele entende que o homem percebeu a importância de uma nova mentalidade em favor da conservação e preservação do meio ambiente, e que é indispensável para a manutenção da vida humana na terra. Para o autor, a própria história aponta que muitos fatores contribuíram para que a situação chegasse a esse ponto, e "o capitalismo, o individualismo, o consumismo e a globalização" são alguns destes elementos (BAUMAN, 2011, p.21). Ramos (2003) defende a importância em dar início a um aprendizado individual e coletivo que leve a humanidade a outras formas de manifestação concreta de sua natureza e que traga uma perspectiva de mudança real e prática em seu modo de viver.

A sustentabilidade, como o novo paradigma deste século, segundo Morin (2005), é o grande desafio a ser incluído na vivência diária de todas as pessoas. Para ele, a maior dificuldade é de superar o individualismo que, segundo sua percepção, é o mal da sociedade pós-moderna. Tal superação pode trazer uma compreensão clara da sustentabilidade, oportunizando uma "[...] tomada de consciência de pertencimento a uma mesma 'terra pátria'" além da compreensão da importância da participação em ações positivas neste sentido (MORIN, 2005, p.166-167).

Para Manzini (2011), a transição para a sustentabilidade pode ocorrer de forma drástica e forçada com a chegada de fenômenos catastróficos que obrigarão uma nova postura imediata, ou de uma forma indolor com a escolha de uma mudança imediata e progressiva com a intenção de evitar em longo prazo, situações extremas de escassez de recursos naturais.

É importante ressaltar que atualmente, uma organização não pode simplesmente comunicar a sustentabilidade. O objetivo de uma empresa que busca alcançar o reconhecimento por ser uma organização ambientalmente responsável se resume na transformação "dos processos de produção, em cadeias produtivas não poluentes" (CASTILHOS, 2010, p.125).

Para o autor supracitado, se a organização consegue ser bem sucedida nesse processo, ela procura trazer essas informações a público para destacar à sociedade e seu público alvo que é uma empresa ética e que está cumprindo com seu papel de ser uma empresa que possui, de fato, 
responsabilidade ambiental (CASTILHOS, 2010).

Para disseminar essas informações para a sociedade e seus consumidores, Filho (2004), destaca o uso da publicidade como uma ferramenta de comunicação da empresa. A publicidade é capaz de trazer benefícios na medida em que um trabalho contínuo pode resultar em uma reputação pública sólida, "[...] na qual a instituição em questão será considerada uma referência, no quesito de excelência e qualidade" (FILHO, 2004, p.185).

Deste modo, pode-se perceber que as empresas já não são mais vistas apenas como parte de um mercado e, sim, pertencentes a uma sociedade global, onde são cada vez mais cobradas por seu desempenho, seja ele de cunho econômico, sobre seu impacto ambiental como organização e em sua atuação social. Dentro deste cenário de sustentabilidade e responsabilidade social, podemos destacar o marketing relacionado a causas (MRC) (BIGLIONE E WOODS, 2007).

O marketing relacionado às causas vem de encontro ao Marketing 3.0, onde as ações de comunicação estão voltadas aos valores. "Em vez de tratar as pessoas simplesmente como consumidoras, os profissionais de marketing as tratam como seres humanos plenos: com mente coração e espírito" (KOTLER, 2010, P. 4).

Para Kotler (2010, p. 4), o Marketing 3.0, promove a busca de soluções para cada um de seus clientes, com o objetivo de satisfazer seus desejos tornando esta época globalizada um mundo melhor. Nesse sentido as organizações que praticam o Marketing 3.0 têm uma contribuição maior em termos de missões, visões e valores a apresentar ao mundo; seu objetivo é oferecer soluções para os problemas da sociedade. Sendo assim, pode-se dizer que as organizações que em suas ações promovem a sustentabilidade, estão exercendo o Marketing 3.0.

Desta forma, é possível afirmar que ações sustentáveis, investimento em causas que estão ligadas à visão da empresa e que estão bem alinhadas com as ações de comunicação e marketing, trazem maior visibilidade à organização. Além disso, tais ações promovem uma identificação maior entre os clientes e sua marca, já que o consumidor percebe que suas necessidades emocionais também estão sendo consideradas. Desta forma, as empresas agregam valor à sua marca e um lugar no coração de seus clientes. (OLIVEIRA, 2013).

\section{Consumo Sustentável}

Levando em consideração o relatório Brundtland, a preocupação e a adoção de práticas sustentáveis podem ser entendidas como uma ação rumo a um consumo sustentável. $O$ termo consumo sustentável nasceu também dentro das discussões da Comissão Mundial sobre o Meio Ambiente, em 1987, quando foi levantada como proposta a seguinte definição: "consumo sustentável é o desenvolvimento que atende às necessidades do presente, sem comprometer a capacidade das futuras gerações em atenderem às suas" (Relatório Brundtland, 1987, p.87).

$\mathrm{Na}$ atualidade, existe uma necessidade urgente, de tomar práticas a fim de motivar mais pessoas ao consumo sustentável. Pois é de extrema importância adotar uma alternativa eficaz de transformação para uma sociedade de baixo carbono e pró-ativa a fim de transformar a relação entre produtores e consumidores. $E$, em consequência disso, construir uma base sólida com novos conceitos, criando uma visão crítica do ato de consumir (SANTOS, 2000).

O surgimento de uma forte tendência relacionada ao comportamento do consumidor nos últimos anos, no Brasil e em vários países em desenvolvimento, está diretamente ligada à 
preocupação em ter e manter uma vida saudável. No Brasil existe uma fatia da população que cresce constantemente disposta a investir grande parte do seu tempo e de seus recursos para viver mais e melhor (VENTURA, 2003).

De acordo com o Instituto Akatu (2007), o consumidor brasileiro tem se mostrado cada vez mais preocupado com a aquisição e o uso de produtos e serviços de cunho sustentável. De acordo com a pesquisa realizada pelo Instituto Akatu, um terço dos consumidores brasileiros considera a responsabilidade socioambiental das empresas na hora de escolher de quem vai comprar.

De acordo com pesquisa realizada através do IDIS ${ }^{1}$ e que foi apresentada no II Seminário Internacional de Marketing Relacionado a Causas, em 2005, destaca-se que 91\% dos brasileiros entrevistados acreditam na importância das empresas apoiarem causas sociais. Dos consumidores entrevistados, $38 \%$ afirmaram ter adquirido produtos ligados a causas sociais e socioambientais pela oportunidade e $58 \%$ compraram por saberem que contribuiriam para a sociedade (IDEIA SUSTENTÁVEL, 2005).

Diante da necessidade, de promover o conhecimento sobre a sustentabilidade para os cidadãos brasileiros, diversas leis de regulação ambiental têm sido criadas no Brasil e estão colaborando para tornar a sustentabilidade um aspecto mais palpável e claro para a sociedade brasileira. Nesse contexto, o consumidor brasileiro desejará obter cada vez mais informações sobre os produtos oferecidos, desde a aquisição de matérias-primas, seu processo de fabricação, até seu destino final. Conhecer a composição, as condições de processamento e transporte e os fabricantes dos componentes do produto são alguns exemplos de informação que serão exigidas (INSTITUTO AKATU, 2007).

\subsection{Decisão de Compra}

Para Solomon (2008), a compra realizada pelo consumidor é uma resposta para a necessidade de um novo produto ou serviço, onde o consumidor percebe essa necessidade e a partir dela, passa a seguir uma série de passos para isso. Os passos abordados por ele são: o reconhecimento do problema, busca de informações, avaliação de alternativas e escolha do produto.

Para Solomon (2008), a cultura do consumidor pode definir as preferências na decisão de compra, atribuídas a diferentes serviços e produtos. A cultura do consumidor também tem o poder de definir as conquistas ou fracassos de produtos e serviços específicos. Um produto que proporciona benefícios de acordo com o que os membros de uma cultura esperam, tem maiores chances de alcançar uma grande fatia do mercado.

Uma das características importantes para compreender o processo de decisão de compra do consumidor é o entendimento de como é o elo entre suas características de consumo, os estímulos de marketing que recebe e a compra efetivamente realizada (BLACKWELL, 2005).

Para Kotler (2010, p. 49), as empresas e seus profissionais de marketing, têm negligenciado os componentes básicos do ser humano na hora de vender seus produtos e serviços. Seguindo a proposta do marketing 3.0 de Kotler, as marcas precisam ir de encontro às "[...] necessidades física, mental, emocional e espiritual [...]" do consumidor.

\footnotetext{
${ }^{1}$ IDIS - Instituto para o Desenvolvimento do Investimento Social - é uma organização civil de interesse público, que tem como objetivo promover e estruturar o investimento de empresas como ferramenta de desenvolvimento para uma sociedade mais justa e sustentável.
} 
O produto pode ser bom, eficaz, e atingir os objetivos esperados, mas a marca precisa ir além, as empresas precisam alcançar o coração dos consumidores. Pois esse envolvimento emocional com as marcas é capaz de criar vínculos afetivos que perdurem por anos. Nesse sentido o marketing 3.0 pode contribuir com estratégias envolver todas as áreas do consumidor, através do fortalecimento da identidade da marca, de sua integridade e imagem (KOTLER, 2010).

Os clientes buscam marcas que defendam suas causas. As empresas que conseguem entender as preocupações dos consumidores e incluí-las também em seus valores como organização, conseguem efetivamente gerar credibilidade e confiança junto de seus clientes (KOTLER, 2010).

\section{Conceito de Embalagem}

A embalagem é um recipiente ou invólucro que armazena produtos temporariamente, individuais ou agrupando unidades, tendo como principal função protegê-lo e alongar o seu tempo de vida, proporcionando sua distribuição, identificação e consumo (ABRE, 2015).

Atualmente sabe-se da necessidade que as embalagens têm no cotidiano das pessoas e da quantidade imensa de opções disponíveis para cada tipo de produto. As marcas evoluíram e também as embalagens. A necessidade de diferenciação das marcas passou a ser fundamental para que os produtos tenham destaque no mercado (NEGRÃO E CAMARGO, 2008).

Segundo Negrão e Camargo (2008), além de proteger e transportar, a embalagem informa, identifica e promove produtos e marcas. Segundo os autores, a embalagem se tornou uma ferramenta essencial para a área da alimentação, saúde e conveniência com a finalidade de disponibilizar produtos com segurança e informação para o bem-estar das pessoas, possibilitando a acessibilidade a produtos frágeis, perecíveis com alto ou baixo valor agregado.

Deste modo, a embalagem também pode representar o fator de diferenciação entre vários produtos da mesma categoria, oferecendo importante vantagem competitiva. Existe enorme relevância das embalagens no sentido de gerar a identidade do produto e que, simultaneamente, funcionam como um poderoso instrumento de vendas. (SERAGINI, 2006).

Na visão de Manzini (2011), muitas vezes uma embalagem pode ser considerada, para todos os efeitos, como um produto que tem o seu próprio ciclo de vida. A seguir seguem três indicações consideradas importantes por Manzini (2011, p.126):

\footnotetext{
- evitar excesso de embalagens para um mesmo produto;

- utilizar material somente onde for realmente útil;

- projetar a embalagem como parte integrada do produto.
}

Para Negrão e Camargo (2008) é importante conhecer os 3R's (Reduzir, Reutilizar e Reciclar) e iniciar, a aplicação desses princípios de forma consciente em cada projeto de embalagem e na vida cotidiana:

- Reduzir: Perceba o que realmente é essencial. Racionalize ao máximo a quantidade de material utilizado na embalagem. Parece óbvio, mas o mercado às vezes impõe que o tamanho da embalagem seja bem maior que o necessário, para que o produto pareça maior do que realmente é e o consumidor tenha a sensação de que está levando mais por menos preço;

- Reutilizar: pensar na aplicação desse princípio ao desenvolver embalagens que não terão 
descarte imediato, mas que possam ser reutilizadas pelo usuário de outras formas, como potes, copos de vidro e caixas, por exemplo;

- Reciclar: pesquisar materiais alternativos que permitam a reciclagem, substituindo substratos convencionais. O custo não deve ser o único parâmetro a nortear essa decisão, uma vez que uma embalagem reciclável revela uma preocupação com o meio ambiente e contribui positivamente para consolidar a imagem da empresa em relação a preocupação com a sustentabilidade.

De acordo com o apresentado, tais desafios foram agrupados em três aspectos. Aspectos estéticos: devem despertar o interesse e evidenciar os padrões de qualidade do produto; aspectos técnicos: precisam garantir a integridade dos benefícios referentes ao transporte, uso e armazenagem e potencializar a funcionalidade do produto durante sua aplicação; e, por último, aspectos ambientais: a embalagem deve ser vista em todo seu ciclo de vida, considerando seus impactos durante o consumo e no pós-consumo, com seu reaproveitamento ou descarte (NEGRÃO E CAMARGO, 2008).

Em pesquisa realizada pela $\mathrm{POPAl}^{2}$, no ano de 2004, com 1860 consumidores, foram apurados dados interessantes sobre o papel da embalagem na decisão de compra. No Brasil, $81 \%$ dos consumidores entrevistados, optam entre uma marca ou outra no local da venda. O consumidor brasileiro é o que mais age dessa maneira de acordo com os dados, Deste modo os profissionais de marketing, comunicação, design e as próprias empresas possuem bons argumentos para investirem em embalagem (POPAI Brasil, 2004).

A pesquisa também destacou que $79 \%$ dos entrevistados consumiram um produto novo por causa da embalagem que despertou sua atenção. Dentro da mesma pesquisa identificou-se que $53 \%$ dos consumidores adquiriram novamente determinados produtos em função de sua embalagem e $46 \%$ dos consumidores avaliados trocaram de marca em função de experiências negativas com uma nova embalagem (MWV, 2015).

As embalagens deixaram de exercer um papel secundário na indústria e passaram a se tornar tão importantes quanto os produtos contidos nelas. Na atualidade, surgiu o termo embalagens inteligentes que, além de práticas, bonitas, invioláveis e informativas para o consumidor são vistas como fortes aliadas para as indústrias enfrentarem a guerra da modernidade e da concorrência (BURNETT, 2005).

Burnett (2005) afirma que a embalagem adequada é um vendedor passivo e mudo. A embalagem inteligente, que é projetada de forma estratégica, agrega valor à marca e é capaz de encantar o consumidor. Ela consegue refletir a identidade e valores da organização e no momento de decisão da compra a embalagem inteligente é capaz de pegar o consumidor pela mão.

\section{Design Estratégico}

O design estratégico, com sua visão sistêmica, pode proporcionar integração a uma empresa ao contribuir de forma eficaz em áreas tais como engenharia, marketing, ergonomia, o design de métodos novos de produção até novos métodos de análise de mercado. Gerando, desta forma, um trabalho muito mais eficiente do que cada área atuar de forma isolada das demais. Sob

\footnotetext{
2 O POPAI Brasil é uma associação sem fins lucrativos, dedicada ao desenvolvimento da atividade de Merchandising, de forma a beneficiar os consumidores; gerar os melhores resultados para os clientes: indústria, comércio e empresas de serviços.
} 
esses aspectos pode-se dizer que o que torna o design estratégico um recurso valioso, não são as habilidades de projetar, colorir ou formatar, mas a habilidade de contribuir em todos os setores de uma organização de forma a estimular, interpretar e sintetizar as informações e transformá-las em produto (LORENZ, 1986).

De acordo com a visão de Magalhães (1997), o designer precisa ter conhecimento sobre o mercado em que a marca está inserida, tendo claros os benefícios que o produto possui e como os consumidores avaliam tais benefícios. Também o modo como selecionam suas aquisições, a fim de transmitir esse valor ao mercado através da visibilidade do produto oferecido. Assim, de acordo com o autor supra citado, pode-se entender que o design estratégico "é um valor a ser oferecido aos consumidores e a sociedade".

Deste modo pode-se dizer que "o design estratégico materializa-se quando o importante é desenvolver o produto certo - eficácia do processo de design - e não somente desenvolver corretamente o produto - eficiência no processo de design". (MAGALHÃES, 1997, p.26)

De acordo com o anteriormente exposto, pode-se afirmar que o design estratégico está envolvido do início ao fim de um projeto, desde sua concepção, pesquisa, desenvolvimento, produção e lançamento do novo produto. Quanto ao designer, ao estar "equipado unicamente com atitudes e habilidades interdisciplinares, o designer senta no centro de uma matriz multidirecional, com um olho (e uma influência) sobre todas as dimensões" (MAGALHÃES, 1997, p.25). Assim, "o design estratégico se torna uma ferramenta para otimização de processos e diferenciação competitiva" (MAGALHÃES, 1997, p.26).

\subsection{O Design Estratégico e a Sustentabilidade}

Para Vezzoli (2008), é na fase de concepção de um produto que os impactos ambientais causados por ele serão definidos. Deste modo, o design estratégico tem importante papel na contribuição para a sustentabilidade, pois é capaz de favorecer sistematicamente a empresa, consumidor e sociedade, compondo produtos que gerem menos impacto ao meio ambiente. Através do design estratégico os valores buscados pela empresa são transformados em produtos.

Um dos grandes diferenciais do design estratégico consiste em sua organização estruturada. O processo para a concepção de produtos envolve uma série de questionamentos que antecedem qualquer processo a ser realizado: para que público, onde será distribuído, de que forma e por que. Mas para que o processo aconteça de forma satisfatória a comunicação interna da empresa, com as equipes envolvidas precisa ser clara e objetiva, já que o design estratégico envolve mudanças em todas as fases do produto (ZURLO, 2010)

Quando o design estratégico considera a sustentabilidade em seu projeto como quesito de prioridade, gera uma ampliação de seu conceito e agrega questões que partem desde a preocupação com as primeiras ações do desenvolvimento do projeto voltadas para as necessidades ambientais e ecológicas que vão permear todo o ciclo de vida de um produto (MANZINI, 2011).

Para Manzini (2011), através do design estratégico é possível concretizar os requisitos típicos de um projeto que são funcionalidade, tecnologia, aspectos econômicos, cultura, legislação e estética. Para Manzini (2011, p.106), as estratégias necessárias são: 
materiais, processos e fontes energéticas de maior ecocompatibilidade;

- otimização da vida dos produtos ao projetar artefatos que perdurem;

- extensão da vida dos materiais ao projetar em função da valorização (reaplicação) dos materiais descartados;

- facilidade de desmontagem ao projetar em função da facilidade de separação das partes e dos materiais.

Deste modo, pode-se afirmar que uma solução sustentável realizada através do design estratégico é o processo através do qual, produtos serviços e até mesmo conhecimentos são organizados em um sistema que tem por objetivo facilitar ao usuário um resultado condizente com os critérios da sustentabilidade. Ou seja, um resultado que tenha a capacidade de gerar transformação em um sistema existente, gerando um novo, que seja coerente dentro dos fundamentais princípios da sustentabilidade, alinhado com os objetivos que permeiam a sustentabilidade, utilizando-se baixa intensidade de energia e material, mas que contenha um alto potencial regenerativo (MANZINI, 2008).

Os benefícios do design estratégico para as embalagens consistem em toda a análise de projeto, pesquisa e acompanhamento de processos onde a criação de uma embalagem não estará ligada somente a aspectos estéticos e comerciais. A embalagem será projetada de acordo com as necessidades do cliente, da empresa, e da sociedade, visando cada processo de produção, orçamento, mercado e visibilidade (NEGRÃO E CAMARGO, 2008).

Nesse sentido, pode-se dizer que o desenvolvimento de embalagens através do design estratégico busca uma combinação entre cada necessidade, que consiste em sua função específica, como envoltório do produto que informa e protege, sua ação como canal de venda e comunicação com o cliente, com formato e matérias-primas que se enquadrem à necessidade da empresa e do mercado e que ainda contribuam no descarte e pós-uso. Ou seja, o design estratégico atua em todas as áreas que nortearão as estratégias a serem seguidas (NEGRÃO $E$ CAMARGO, 2008).

Através do design estratégico é possível tornar perceptível os valores de uma organização. De acordo com Magalhães (1997) "No design estratégico (na fase inicial do processo de desenvolvimento de produto), a forma segue primeiramente a função de comunicar [...]." Assim, a embalagem torna-se um meio de comunicação entre a marca e seus consumidores, onde a preocupação do design estratégico é representar através das embalagens, todas as necessidades e benefícios esperados pelo cliente, através das funções práticas, estéticas ou por funções simbólicas. "Sendo assim, para um design estratégico a forma segue a mensagem" (MAGALHÃES, 1997, p.28).

\section{A Natura}

Fundada em 1969, por Antonio Luiz Seabra, a marca Natura, que se tornou referência no mercado de cosméticos no Brasil, iniciou suas atividades com um laboratório e uma pequena loja de cosméticos, através da colaboração de sete funcionários que comercializavam os produtos e prestavam consultoria de beleza. A marca contava com embalagens bem simples, praticamente artesanais que tornavam inviável a comercialização com canais tradicionais de venda que poderiam dar mais acesso aos consumidores finais (MUNDO DAS MARCAS, 2011).

Atualmente, e ao longo de seus 46 anos de história, a Natura dedica-se a construir uma imagem de respeito com seus funcionários, clientes, fornecedores e principalmente com o meio 
ambiente. A marca tem posição de destaque no cenário empresarial brasileiro, uma das marcas mais respeitadas no país. A história que iniciou com aquela pequena loja, sob a direção de Luiz Seabra acompanhado de seus sócios, conquistou ao longo dos anos uma rede com mais de 1,5 milhão de revendedores em 2012, tornando-se líder na venda de cosméticos no país, além de estar colocada como a quinta maior companhia em vendas diretas do mundo, chegando ao faturamento de 8,5 bilhões de reais naquele ano (EXAME, 2013).

A Natura buscou um novo desafio de negócio, com a tarefa de trazer um novo conceito e uma nova proposta de valor para o consumidor, com o objetivo de introduzir a marca em um espaço no mercado que até então não ocupava. Tendo como objetivo ocupar um espaço intermediário de preço, a Natura tomou uma série de medidas para desenvolver uma linha que contivesse toda a qualidade Natura, com todo o potencial e valores que a Marca Natura possui, mas que oferecesse um preço acessível aos consumidores (CASE NATURA SOU, 2013).

Para a concepção dessa linha a Natura trabalhou com duas agências de confiança Tátil e Questto Nó. O trabalho a ser realizado deveria encontrar soluções eficientes para todo o processo de desenvolvimento da linha, tornando possível eliminar tudo o que fosse desnecessário, e acabar de vez com a ideia de que produtos que possuam baixo impacto ambiental sejam caros. Ou seja, o desafio foi criar um produto ambientalmente responsável, porém com um custo acessível (QUESTTO NÓ, 2015). Assim nasceu a linha Natura Sou.

Para a Natura, o principal objetivo era mostrar através da linha Sou que um produto sustentável não precisa ser caro. A marca preocupou-se em estabelecer como meta para a linha, um impacto ambiental tão baixo, a ponto de eliminar a necessidade de haver refis para seus produtos, como são feitos para as outras linhas da Natura (CASE NATURA SOU, 2013).

A solução encontrada com base em toda a etapa de pesquisa utiliza em sua composição, $70 \%$ menos plástico que as embalagens convencionais, garantindo redução no uso de matériaprima, e uma extração que garante menor impacto ambiental, com diminuição de $50 \%$ da poluição, comparada com outras linhas do segmento (QUESTTO NÓ, 2015).

Para a equipe, o uso do design estratégico, tornou-se importante, pois o trabalho criativo se deu em todas as instâncias do produto, tornando possível aprimorar cada fase de desenvolvimento, em todas as etapas do seu ciclo de vida. Também através do design estratégico foi possível atribuir às embalagens os objetivos da marca Natura, atuando nos pilares do design estratégico que envolve a preocupação com a empresa, sociedade e consumidor (QUESTTO NÓ, 2015).

\section{Metodologia}

Quanto à metodologia, esta pesquisa se deu através de estudo exploratório, sendo caracterizada como qualitativa e, quanto às técnicas, foram utilizadas a pesquisa documental e o grupo focal. A técnica documental foi aplicada no presente estudo, a partir de análises de publicações, de sites corporativos da Natura, blogs e portais de notícias online. Quanto ao grupo focal foi utilizado como forma de coleta de dados com a finalidade de gerar conhecimento sobre as percepções de sustentabilidade nas embalagens Natura Sou. Para isso, foi elaborado um roteiro de pesquisa e estratégias com o objetivo de estimular a discussão, incluindo preparação, planejamento, seleção de materiais, definição dos participantes, local a ser realizada a pesquisa e o levantamento de pontos chave a fim de direcionar a pesquisa e o embasamento teórico das análises (BARBOUR 
2009).

\section{Análise dos Dados}

As informações analisadas foram subdividas em categorias para a melhor representação dos resultados como também para proporcionar um melhor entendimento sobre os pontos abordados na pesquisa.

\subsection{Quanto ao consumo de produtos cosméticos}

Para a maioria das participantes entrevistadas, os benefícios que o produto pode proporcionar como textura, perfume e qualidade são os fatores decisórios na aquisição de um produto cosmético. Seguindo a discussão, 8 das 9 entrevistadas mencionaram a influência que a opinião de um amigo exerce sobre a escolha do produto, como afirma a participante 2 ao dizer que "pra mim o que influencia é se uma amiga disse que usou e achou muito bom. Eu confio e compro pela indicação.".

O destaque dado à indicação de amigos e formadores de opinião vem de encontro com a afirmação de Negrão e Camargo (2008, p.64): "somos influenciados pelo grupo social ao qual pertencemos. O grupo a que você pertence direciona parcialmente o tipo de consumo que fará". Para Solomon (2008, p.31), mais do que nunca as empresas precisam empenhar-se em ouvir seus consumidores, "[...] a chave para o sucesso é a construção de laços, entre marcas e clientes, que possam durar a vida toda". São estes elos que irão permitir que o cliente escolha produtos sem precisar de indicações, testes ou qualquer prova de que são bons, pois a marca transparece a confiança e credibilidade capazes de atestar os benefícios do produto.

\subsection{Quanto a linha Natura Sou}

De acordo com as percepções das participantes a respeito das embalagens da Natura Sou, a participante 4 acrescenta: "o bom desta embalagem é que posso usar tudo", essa afirmação foi concordada pela participante 1 que disse não gostar da embalagem ao início da conversa e, juntas, chegaram ao consenso que uma alternativa para a embalagem ficar de pé resolveria o problema abordado pela participante 1. Ainda sobre a estrutura da embalagem, a participante 6 afirma: "eu gosto porque é como pasta de dente dá pra espremer e usar até o final".

De acordo com Negrão e Camargo (2008, p.119), "é por intermédio de uma boa embalagem, ergonômica e funcional, por exemplo, que podemos ainda aperfeiçoar a aplicação e o uso do produto". Neste caso, as embalagens Natura Sou, foram cuidadosamente pensadas e desenvolvidas para permitir o máximo de uso do produto contido em suas embalagens.

Para a participante 2, o ponto forte da embalagem é o fato de conter menos plástico que outras embalagens. Essa característica positiva foi aprovada por todas as participantes, sendo que a participante 5 complementa: "é 70\% menos plástico". Também esclarecendo que um dos motivos do valor ser mais acessível é justamente por usar menos plástico que outras embalagens e menos matéria prima em sua composição.

Sabe-se que hoje as embalagens possuem um impacto direto no preço de um produto final. Pois, dependendo do produto oferecido, a embalagem possui a maior parte dos elementos que estarão compondo o produto. Neste caso pode-se dizer que o desenvolvimento das embalagens e os materiais utilizados implicarão diretamente no valor final do produto. Uma forma de conter os custos é investir em ideias que se utilizem de menos matéria prima a fim de gerar 
mais lucratividade para as empresas e um custo mais acessível ao consumidor final (NEGRÃO E CAMARGO, 2008).

Após as colocações feitas a respeito das embalagens, a moderadora levantou o questionamento sobre os motivos que levaram as participantes a consumirem os produtos da linha. A participante 1 fala que sua motivação é impulsionada através do valor praticado pela linha: "quando vi o preço da linha Natura Sou quase não acreditei, se compara ao valor dos produtos do mercado". Concordando com a opinião, a participante 3 destaca que o valor é praticado pela Sou é bem inferior às outras linhas vendidas pela Natura, mas que em nenhum momento os produtos perdem em qualidade.

\subsection{Quanto à sustentabilidade}

Dando sequência à pesquisa, a moderadora questiona as participantes sobre o que elas entendem por sustentabilidade. A partir da proposta, iniciou-se a discussão através da colocação da participante 2: "acho que tem a ver com a preocupação com o planeta e com o meio ambiente". Sua opinião foi complementada pela participante 7 que destacou que para ela, significa a preocupação com todos os processos que dizem respeito ao produto, "desde o comecinho até chegar no produto final, pra mim isso é sustentabilidade".

Em complemento às opiniões das participantes, na visão de Enlazador (2010), a obrigação e as novas posturas são responsabilidade de todos e devem dirigir todas as ações de cada cidadão em qualquer escolha que tomar, pois são os pequenos passos que levarão à construção de uma cultura sustentável.

As colocações feitas acima estão de acordo com a visão de uso do design estratégico para a criação de produtos sustentáveis que buscam visualizar além do que é percebido hoje, criando soluções que se convertam em produto sustentável e que levam em consideração todo o ciclo de vida do produto. "Deste ponto de vista, portanto, todas as atividades necessárias para produzir, distribuir, utilizar e eliminar/descartar um produto são consideradas uma só unidade". (MANZINI, 2011, p.100)

Em seguida, a moderadora ainda questiona se as participantes poderiam afirmar que a Linha Natura Sou é sustentável, levando em consideração o que foi exposto sobre a sustentabilidade. E se, através da embalagem elas podiam perceber a sustentabilidade. Prontamente, todas afirmaram que sim e para complementar a pergunta a participante 6 acrescenta: "Acho que sustentabilidade também é se preocupar com o desperdício e com essa embalagem conseguimos usar o produto por inteiro", assim também sugeriu que todos os refis poderiam utilizar o mesmo material para que o produto possa ser usado ao máximo.

\section{Considerações Finais}

Indo de encontro à todos os temas abordados, pode-se entender que o design estratégico desempenha importante função quanto a representação da sustentabilidade através de produtos, já que uma das preocupações dentro do design estratégico é justamente desenvolver soluções que atendam os objetivos buscados pela empresa, levando em consideração todos os valores que a marca busca transmitir através de seus produtos.

O grande destaque da linha Natura Sou, está justamente no uso da abordagem do design estratégico na concepção de seus produtos. Dessa forma, foi possível unir fatores como a 
preocupação com a sustentabilidade, o padrão de qualidade Natura, e o preço. Ou seja, na concepção da linha Natura Sou foram levados em consideração a sociedade, a empresa e o consumidor, que são os pilares do design estratégico.

Vindo de encontro às respostas encontradas pode-se identificar que as consumidoras percebem a sustentabilidade nas embalagens, mas ela não é o motivo pelo qual a maioria delas compra os produtos da linha. Isto demonstra que mesmo que cada uma saiba da importância da sustentabilidade, o que ainda fala mais alto na hora de escolher o produto é a qualidade e principalmente a marca Natura.

É importante levar em consideração quais os objetivos que a Natura, como organização, busca através da Linha Natura Sou. O preço, que foi um dos principais objetivos buscados, realmente abriu uma nova fatia de mercado para a organização e é reconhecida como um fator na decisão de compra, de acordo com as entrevistadas. O que torna a linha bem sucedida neste sentido.

Dessa forma, conclui-se que é importante adotar o design estratégico no desenvolvimento de produtos, pois ele traz para o processo de concepção, tudo o que é importante para a empresa, para a sociedade e consumidor.

O design estratégico na criação de embalagens sustentáveis colabora com o meio ambiente, com a qualidade de vida, além de proporcionar a obtenção de ideias mais econômicas, funcionais, inovadoras e com visual que proporcione mais proximidade e comunicação direta com o cliente final.

Através da percepção dos consumidores da cidade de Três Coroas sobre as embalagens Natura Sou, foi possível identificar que todas as clientes aprovaram o produto, atestando sua qualidade, aroma agradável e preço muito acessível. Embora a sustentabilidade seja percebida e bem defendida por algumas clientes que compram por esse motivo os produtos da linha, a decisão de compra para a maioria das clientes, em ordem de relevância, é a qualidade, a marca Natura, o preço e em seguida a sustentabilidade, como foi mencionado anteriormente. Assim também foi possível perceber o peso que a marca Natura exerce como fator decisório na compra de quaisquer produtos da marca.

Visto que através do grupo focal obtiveram-se resultados inesperados e que a pesquisa decorreu através de um número de participantes pré-estabelecidos como amostragem, sugeremse novos estudos com relação à percepção dos consumidores e também de não consumidores, a fim de avaliar as diferentes percepções. Sugere-se também a ampliação das regiões abordadas a fim de aprofundar a visão com relação à percepção da sustentabilidade na linha Natura Sou, a fim de comparar os resultados por região.

\section{Referências}

ABRE. A embalagem. In: ABRE, 2015. (http://www.abre.org.br/setor/apresentacao-do-setor/aembalagem)

ALMEIDA, F. O bom negócio da sustentabilidade. Rio de Janeiro: Nova Fronteira, 2002.

BARBOUR, Rosaline. "Grupos focais." Porto Alegre: Artmed, 2009.

BAUMAN, Zygmunt. A ética é possível em um mundo de consumidores? Tradução: Alexandre Werneck. Rio de Janeiro: Zahar, 2011. 
BLACKWELL, Roger D.; MINIARD, Paul W.; ENGEL, James F. Comportamento do consumidor. São Paulo: Thomson Learning, 2005.

BURNETT, Leo. Embalagens ativas. In: Revista Fapemig, 2015. (http://revista.fapemig.br/materia.php?id=159)

BRUNDTLAND, Comissão. Nosso Futuro Comum, Relatório sobre Desenvolvimento Sustentável. ONU, 1987.

CASE NATURA SOU. Processo Criativo. In: 2013. (https://www.youtube.com/watch?v=F5MaFipe8-E)

CASTILHOS, Zuleica Carmen, et al. Metodologia para o monitoramento da qualidade das águas da Bacia Carbonífera Sul Catarinense: Ferramenta para gestão em poluição ambiental. Série Gestão e Planejamento Ambiental 13. 2010.

ENLAZADOR, Thomas. Almanaque de práticas sustentáveis. 3a ed. Recife: 2010.

EXAME. Chegou a gora de mudar. In: Exame, 2105. (http://exame.abril.com.br/revistaexame/edicoes/1042/noticias/chegou-a-hora-de-mudar)

FILHO, Genauto Carvalho, and Jean-Louis Laville. Economia solidária: uma abordagem internacional. UFRGS Editora, 2004.

IDEIA SUSTENTÁVEL. Ferramenta - O marketing relacionado à causa e à comunicação do investimento social privado. In: Ideia 2005. (http://www.ideiasustentavel.com.br/2005/12/ferramenta-o-marketing-relacionado-a-causa-e-acomunicacao-do-investimento-social-privado/)

INSTITUTO AKATU. Responsabilidade social das empresas. Percepção do consumidor brasileiro. In: $\quad$ AKATU, 2010.

(http://www.akatu.org.br/Content/Akatu/Arquivos/file/10_12_13_RSEpesquisa2010_pdf.pdf)

KOTLER, Philip. Marketing 3.0: As Forças que Estão Definindo o Novo Marketing Centrado no Ser Humano. Rio de Janeiro: Elsevier, 2010.

LORENZ, C. The Design Dimentions: the new competitive weapon for business. Oxford, UK, Brasil Blackwell, 1986.

MAGALHÃES, Claudio Freitas de. "Design estratégico: integração e ação do design industrial dentro das empresas." Rio de Janeiro: SENAI/DN, SENAI/CETIQT, CNPq, IBICT, PADCT, TIB, 1997.

MANZINI, Ezio. Design para a inovação social e sustentabilidade: comunidades criativas, organizações colaborativas e novas redes projetuais. Rio de Janeiro: E-papers (2008).

; VEZZOLI, C. O desenvolvimento de produtos sustentáveis. Os requisitos ambientais dos produtos industriais. 3a ed. São Paulo: Edusp, 2011.

MARIOTTI, Humberto. Complexidade e sustentabilidade: o que se pode e o que não se pode fazer. São Paulo: Atlas, 2013.

MORIN, Edgar. 0 método 6: ética. Porto Alegre: Sulina, 2005.

MUNDO DAS MARCAS. Natura. In: 2011. (http://mundodasmarcas.blogspot.com.br/2006/05/natura-natureza-viva.html). 
MWV. Pesquisa 2015. In: MWV, 2015. (http://www.mwv.com/en-us/about/packaging-matters)

NEGRÃO, Celso; CAMARGO, Eleida. Design de embalagem: do marketing à produção. São Paulo: Novatec, 2008.

OLIVEIRA, Ivone de Lourdes. Dimensão estratégica da comunicação no contexto organizacional contemporâneo: um paradigma de interação comunicacional dialógica. Rio de Janeiro, UFRJ. 2003.

POPAI - The Global Association for Marketing At Retail. Estatísticas. In: POPAl, 2015. (http://www.popaibrasil.com.br/)

QUESTTO NÓ. Natura Sou. In: Natura, 2015. (http://www.questtono.com/?p=4398\&lang=pt)

RAMOS, P. Desenvolvimento, excedente, desperdício e desigualdade: a insustentabilidade de nosso modo de vida. In: Martins, R.C.; Valencio, N. F. L. S. (org.) São Carlos: Rima, 2003. V. 2.

RIBEIRO, M. A. Pensando o ambiente humano. In: Ecologizar, 2015. (http://www.ecologizar.com.br).

SANTOS, Milton. Por uma outra globalização: do pensamento único à consciência universa. Ed. Record, São Paulo, SP. 2000.

SERAGINI, L. Meta: criar gestores de embalagem. Embalagem Marca, São Paulo, ano 6, n.79, p.85 -88 , mar. 2006.

SOLOMON, Michael. Comportamento do Consumidor-Comprando, possuindo e sendo, 6a edição, 2008.

VENTURA, Rodrigo. Mudanças no perfil do consumo no Brasil. In: Macroplan, 2015. (www.macroplan.com.br/Documentos/ArtigoMacroplan20108171 82941.pdf)

VEZZOLI, Carlo Arnaldo, e Ezio Manzini. Design para a sustentabilidade ambiental. Springer Science \& Business Media, 2008.

ZURLO, Francesco. Design strategico. Gli spazi e le arti 4. Milano, Edizioni POLI.design, 2010. 